\title{
Вопросы государственной энергетической политики в решениях Госкомитета обороны СССР (1941-1945 гг.)
}

Н.С. СИмОнОВ, доктор исторических наук, ПАО «ФСК ЕЭС», Москва. E-mail: SimonovNS@mes-centra.ru

Аннотация. В статье впервые в историографии проведен источниковедческий анализ комплекса документальных материалов, относящихся к деятельности ГКО СССР по управлению электроэнергетикой. Составлен Перечень из 308 постановлений и распоряжений, распределенных по девяти однородным группам управленческих решений. Показано историческое значение решений ГКО от 18 августа 1943 г. по вопросам регулирования частоты тока в электроэнергетических системах и повышения коэффициента мощности электроустановок промышленных предприятий. Данные решения, принятые в переломный период Великой Отечественной войны, предотвратили «блэкаут» Уральской электроэнергетической системы и стимулировали производителей и потребителей электроэнергии к экономному и рациональному использованию энергетических ресурсов.

Ключевые слова: Государственный комитет обороны СССР; лимиты электропотребления; электроэнергетическая система; частота электрического тока; коэффициент мощности промышленных электроустановок

\section{Новые первоисточники по истории электроэнергетики СССР периода Великой Отечественной войны}

Рассекречивание в 2005 г. полного комплекта постановлений и распоряжений Государственного комитета обороны (ГКО) СССР с подготовительными материалами позволяет более глубоко вникнуть в проблему организации и функционирования военно-мобилизационной экономики и ряда ее базовых отраслей, к которым относятся топливная промышленность, транспорт и электроэнергетика.

По моим подсчетам, с июля 1941 г. по август 1945 г. ГКО принял в сфере электроэнергетики 308 решений, оформленных в виде постановлений и распоряжений, которые затрагивали непосредственно следующие вопросы: 
1) демонтаж оборудования, эвакуация и реэвакуация электростанций (7 решений);

2) оказание помощи электростанциям в выдаче мощности, ликвидация аварийных ситуаций, снабжение дополнительным оборудованием и запчастями, проведение плановых ремонтов, усиление охраны энергетических объектов (53);

3) организация работы территориальных управлений Наркомата электростанций и электроэнергетических систем («Уралэнерго», «Мосэнерго», «Ленэнерго» и др.) (29);

4) обеспечение электростанций топливом (уголь, мазут, торф, дрова) и создание его запасов (58);

5) надежное электроснабжение предприятий военно-промышленного комплекса, экономия электроэнергии и топлива в промышленности и коммунальном хозяйстве (40);

6) планирование выработки и распределения электрической и тепловой энергии электростанциями Наркомата электростанций СССР и ТЭЦ промышленных предприятий на календарный период (21);

7) ввод новых мощностей действующих электростанций, строительство новых электростанций, восстановление энергетических объектов в освобожденных районах (66);

8) использование передвижных (мобильных) электростанций (9);

9) демонтаж, вывоз и установка в СССР трофейного энергетического оборудования (25).

В 1941-1942 гг. ГКО выпустил по вопросам электроэнергетики 30 постановлений и распоряжений, в 1943 г. - 74, в 1944 г. -104 , в 1945 г. $-100^{1}$.

\section{ГКО СССР - чрезвычайный орган регулирования электроснабжения потребителей}

Из литературы о деятельности высшего партийно-государственного руководства СССР во главе с И.В. Сталиным в годы Великой Отечественной войны известно, что после образования ГКО его члены разделили между собой (зафиксировав это письменно) сферы постоянной деятельности.

\footnotetext{
${ }^{1}$ Реквизиты соответствующих документов (номер, название, дата) выделены в отдельный Перечень, который предоставлен редакции журнала «ЭКО» отдельным файлом - для подтверждения выявленной информации.
} 
Электроэнергетика в числе этих сфер не упоминается. Вероятно, это обусловлено тем, что производство, передача и распределение электроэнергии - это условие функционирования любого производственно-технологического комплекса, как военно-промышленного, так и гражданского. Хотя, например, в нацистской Германии министр вооружений Альберт Шпеер в 1942-1945 гг. одновременно являлся и министром энергетики, что особо подчеркивает значение данной отрасли для создания и функционирования технологических цепочек производства военной продукции, начиная от энергоемких предприятий металлургии и «большой химии» и заканчивая сборочными процессами. Большинство постановлений и распоряжений ГКО по вопросам электроэнергетики вышли за подписью заместителя Председателя Совмина СССР В. М. Молотова, как правило, по представлению наркома электростанций СССР (НКЭС) Д.Г. Жимерина или его заместителей.

Из выделенных однородных групп решений особого внимания заслуживает комплекс производственно-технических вопросов, связанных с задачами повышения надежности электроэнергетических систем и эффективности энергопотребления промышленных предприятий в условиях острого дефицита электроэнергии.

В 1941-1942 гг. СССР потерял 60 крупных электростанций суммарной мощностью 6 млн кВт, в том числе Днепровскую ГЭС. Производство электроэнергии в стране сократилось почти в два раза (с 48,3 млрд до 29,1 млрд кВт·ч), поэтому расходовать ее приходилось крайне экономно - в пределах установленных для каждого наркомата, предприятия или учреждения лимитов.

Не только население, но и все промышленные предприятия оказались на «голодном пайке», получая электроэнергию только в установленные часы и в ограниченном количестве. Красочные плакаты с воззваниями: «Экономя киловатты, ты даешь на фронт гранаты», «Наркомвнуделец! Экономя электричество, ты помогаешь фронту!» висели в каждом учреждении и предприятии.

Установление лимитов электропотребления являлось исключительной прерогативой ГКО. На каждый квартал текущего хозяйственного года, иногда с помесячной коррекцией, ГКО утверждал общегосударственный план потребления электроэнергии с разбивкой плановых заданий по основным энергосистемам: Уральской, Горьковской, Московской, Ташкентской, Ярославской, 
Ивановской, Кировской, Казанской, Уфимской, Саратовской, Орской, Куйбышевской, Кузбасской, Омской.

Первое место по выработке электроэнергии в годы войны принадлежало Уралу, который дал в 1943 г. 32,5\%, в 1944 г. $30,6 \%$ и в 1945 г. - 28,3\% всего производства электроэнергии в стране. Районы Центра занимали второе место; их удельный вес во всесоюзном производстве электроэнергии составлял: в 1943 г. $-27,5 \%$, в 1944 г. $-26,4 \%$ и в 1945 г. $-24,2 \%$.

Затем шли Западная Сибирь с удельным весом, соответственно, $10,1 \%, 9,9 \%$ и 9, $4 \%$; Поволжье - 5,6\%, 5,4\% и 5\%; Азербайджанская $\mathrm{CCP}-4,3 \%, 3,9 \%$ и 3,8\%; Северо-Запад - 2,2\%, 2,9\% и 3,9\%; Узбекская ССР-3,6\%, 3,1\% и 2,7\%; Казахская ССР - в течение всех трех лет 2,7\%; Восточная Сибирь -2,8\%, 2,7\% и 2,6\% [Кравченко, 1970].

Получив (квартальный или месячный) лимит электропотребления, а от наркоматов - заявку на распределение его по предприятиям, районные энергетические управления заполняли особые бланки, называвшиеся «лимитными листками», и рассылали их по предприятиям и учреждениям.

Бланк содержал лимиты месячного и суточного расхода электроэнергии, а также нагрузки и расхода электроэнергии на рабочий и выходной дни на каждый месяц и квартал; часы утреннего и вечернего максимума (лимит нагрузки); установленный выходной день.

В 1942-1943 гг. лимиты потребляемой мощности и электроэнергии пересматривались ГКО почти ежемесячно, в зависимости от складывающегося топливного баланса и изменяющихся производственных планов наркоматов.

Превышение лимитов «каралось» отключением потребителей от районных электросетей оперативно-диспетчерскими управлениями (ОДУ) электроэнергетических систем. Поскольку большинство распределительных сетей 0,4-10 кВ того времени проектировались по радиально-петлевому принципу, то отключение одного нарушителя зачастую приводило к вынужденному отключению потребителей по всей длине линии. Естественно, это вызывало жалобы и претензии со стороны предприятий и учреждений, укладывавшихся в установленные нормативы.

18 января 1943 г. ГКО по представлению НКЭС СССР принял постановление № 2756, согласно которому управляющие электроэнергетических систем получили право за превышение расхода электроэнергии против установленных лимитов «накладывать 
на директоров предприятий и руководителей учреждений штраф в размере 700 руб.»².

Имели место случаи «сговора» энергетиков с крупнейшими потребителями, когда руководители электроэнергетических систем без согласования с ГКО вносили изменения в «лимитные листки» отдельных предприятий, увеличивая для них суточный отпуск электроэнергии, в том числе - за счет ее сверхплановой выработки. Для иллюстрации приведем выдержку из служебной записки Наркома электростанций тов. Жимерина Управляющему «Мосэнерго» тов. Мухитдинову от 8 мая 1943 г.:

«Указываю Вам на недисциплинированность в выполнении распоряжений НКЭС о даче объяснений самовольного изменения Вами лимитов отпуска электроэнергии, утвержденных ГКО на март месяц. Разъясняю Вам, что при наличии лимитов, утвержденных ГКО, районные управления или местные партийные и советские организации не имеют права самовольно, без указания ГКО, менять эти лимиты. Ваши объяснения, вместо признания собственной ошибки и обязательства не допускать ее в дальнейшем, преследуют цель смазать эту ошибку и найти оправдывающие мотивы для Вашей недисциплинированности. Примите меры к недопущению в будущем подобных действий. Предупреждаю, что за повторение недисциплинированности Вы будете наказаны» ${ }^{3}$.

\section{Уральская электроэнергетика в 1942-1943 гг.: угроза «блэкаута» и меры по предотвращению распада энергосистемы}

В IV кв. 1942 г. суммарная рабочая мощность всех электростанций Урала достигла 1066 МВт (в январе 1941 г. - 723 МВт). На 2000-километровом протяжении, от Соликамска до Магнитки, формировалась межрайонная энергосистема, в составе которой работали электростанции различной мощности и разных типов.

Основную нагрузку несли 12 тепловых (угольных) электростанций: Челябинская ГРЭС (рабочая мощность 808 МВт); СреднеУральская ГРЭС (149 МВт); Кизеловская ГРЭС (84 МВТ); Закамская ТЭЦ (60 МВт); Егоршинская ГРЭС (24 МВт); Свердловская ГРЭС (10 МВт); Березниковская ТЭЦ (38 МВт); Красногорская

${ }^{2}$ РГАСПИ. Ф.644. Оп.2. Д.127. Л.90.

${ }^{3}$ РГАЭ. Ф.7964. Оп.2. Д.277. Л.103. 
ТЭЦ (200 МВт); Челябинская ТЭЦ (75 МВт); Магнитогорская ЦЭС НКЧермет (114 МВт); ТЭЦ Уралмашзавода НКТанкопром (22 МВт); ТЭЦ завода № 183 НКТанкопром (45 МВт).

Самые большие проблемы для уральской электроэнергетики создавало топливоснабжение. Угля местной добычи - кизеловского и богословского - не всегда хватало, и он был пониженного качества, поэтому котлы электростанций сильно зашлаковывались. Останавливать же их для расшлаковки и текущего ремонта по условиям нагрузки было чрезвычайно трудно, а порой и невозможно.

В 1942 г. на электростанциях ОЭС Урала произошло 435 аварий с повреждением оборудования. В электросетях были зафиксированы 84 аварии, самая тяжелая случилась 5 сентября 1942 г. После поломки опорной колонки разъединителя на подстанции 110 кВ «Дегтярка» при коротком замыкании возникла «лавина напряжения», и после трех «качаний» вся Уральская энергосистема «развалилась» на несколько изолированных узлов. Некоторые города, заводы, шахты, рудники на несколько дней остались без электричества.

Из-за нарушения статической устойчивости энергосистемы в 1943 г. произошли 33 аварии, из-за нарушения динамической устойчивости - шесть. В большинстве случаев причина - отсутствие на электростанциях достаточного резерва в условиях превышения промышленными предприятиями установленных для них лимитов потребления электроэнергии. Например, Кировский завод Наркомата танковой промышленности СССР при среднесуточном лимите расхода электроэнергии в 1,03 млн кВт·ч в сутки систематически расходовал $1,15-1,2$ млн кВт·ч 4 .

25 апреля 1942 г. ГКО выпустил постановление № 1643 «О графике аварийных ограничений по системе Уралэнерго». ГКО подтвердил необходимость соблюдения ежесуточного лимита отпуска электроэнергии потребителям и определил особые меры контроля - обязал прокурора СССР по представлению Наркома электростанций привлекать к судебной ответственности руководителей уральских предприятий и учреждений «за расход электроэнергии сверх установленных Правительством лимитов» ${ }^{5}$.

${ }^{4}$ РГАСПИ. Ф.644. Оп.2, Д.417. Л.63.

${ }^{5}$ РГАСПИ. Ф.644. Оп.2. Д.417. Л.63. 
Во II кв. 1943 г. частота электрического тока в Уральской энергетической системе, производившей $32,5 \%$ всей электроэнергии в стране, снизилась до аварийных 40-42 Гц, и это едва не стало причиной непредсказуемого по своим последствиям «блэкаута» - как раз во время решающего масштабного сражения на Курской дуге. При работе с пониженной частотой на 13 электростанциях произошли поломки лопаток турбогенераторов ${ }^{6}$. Из-за вынужденной остановки энергоблоков на ремонт народное хозяйство недополучило десятки млн кВт·ч электроэнергии.

17 августа 1943 г. наркома электростанций Д.Г.Жимерина вызвали на доклад к Председателю ГКО И.В. Сталину. В опубликованных в 1985 г. воспоминаниях Жимерин пишет, как «с трудом преодолев страх, он в простой и доступной форме» объяснил Сталину, что «понижение частоты происходит из-за снижения числа оборотов турбин, а это связано с их перегрузкой».

- А что нужно сделать? - последовал новый вопрос.

- Разгрузить турбины и уменьшить лимиты энергии потребителям.

- Вы что же, предлагаете остановить уральские заводы? с раздражением спросил Сталин.

- Нет, товарищ Сталин, я этого не предлагаю. Но в расходовании электроэнергии на предприятиях имеются крупные недостатки. $<\ldots>>$

18 августа 1943 г. в ЦК ВКП (б) на рабочее совещание к Г.М. Маленкову были вызваны все наркомы. «Мне, - пишет Жимерин, - было предложено коротко доложить обстановку, разъяснить, какие катастрофические последствия могут произойти, если не будет уменьшена нагрузка энергосистемы. <..>

\footnotetext{
${ }^{6}$ Частота тока в электроэнергетической системе определяется скоростью вращения роторов генераторов, и, следовательно, турбин. Стандартное значение частоты в нашей стране - 50 Гц. Частота тока в электроэнергетических системах, как правило, поддерживается автоматическими регуляторами и при нормальной эксплуатации изменяется в узких пределах. Мощность различных токоприемников может поразному зависеть от частоты. Наиболее чувствительны к ее отклонениям вращающиеся машины. Снижение частоты снижает скорость вращения асинхронных двигателей приводов производственных механизмов, что оказывает технологический ущерб. При снижении частоты уменьшается сопротивление асинхронных двигателей и возрастает потребляемый ими ток, что вызывает дополнительный нагрев статора и ротора и, как следствие, сокращает срок службы двигателя за счет ускоренного износа его изоляции при повышенной температуре.
} 
Возражений было больше, чем нужно, но здесь же было сформулировано постановление Госкомитета обороны о снижении нагрузки, и наркомы завизировали его» [Энергетики в Великой Отечественной войне, 1985].

Наркомы согласились с тем, чтобы, как сказано в постановлении ГКО № 3944 «О мерах обеспечения нормальной частоты в энергосистемах», «считать работу энергетических систем и отдельных электростанций с пониженной частотой преступлением перед государством» ${ }^{7}$.

За переборы установленных лимитов, невыполнение диспетчерских графиков нагрузки и неподчинение диспетчерским распоряжениям по ограничению электропотребления на руководителей и главных энергетиков предприятий, согласно постановлению № 3944, налагался штраф в размере до 1000 руб. ${ }^{8}$

В 1945 г. в Уральской энергосистеме параллельно работали 28 районных электростанций и заводских теплоэлектроцентралей с годовым электробалансом, превышающим 10 млрд кВт·ч. По данным Государственной инспекции по промышленной энергетике и энергонадзору при НКЭС (создана постановлением ГКО № 5928 от 18 мая 1944 г. «Об экономии электроэнергии в промышленности»), в 1944-1945 гг. в Уральской энергосистеме не было зафиксировано ни одной аварии, причиной которой были бы превышение лимитов электропотребления и снижение частоты электрического тока.

\section{Борьба за повышение $\cos \varphi$}

На упомянутом рабочем совещании у Г. М. Маленкова 18 августа 1943 г. Д.Г. Жимерину также удалось согласовать с наркомами проект постановления ГКО, направленного на борьбу с расточительством электроэнергии в производственных процессах.

В Пояснительной записке к постановлению ГКО № 3945 от 18.08.1943 г. «О повышении коэффициента мощности (косинуса фи) промышленных предприятий», сообщалось, что за время, прошедшее с начала Великой Отечественной войны до декабря 1942 г., косинус фи ( $\cos \varphi)$ промышленных предприятий $\mathrm{CCCP}$ в среднем снизился с 0,875 до 0,811. В частности, это привело к непроизводственному расходу электроэнергии в электрических

\footnotetext{
${ }^{7}$ РГАСПИ. Ф.644. ОП.2. Д.205. Л.96.
}

${ }^{8}$ Там же. Л.97. 
сетях в размере 320 млн кВт·ч и к пережогу на электростанциях, как минимум, 200 млн т условного топлива'.

Повысить $\cos \varphi$ можно путем уменьшения (желательно до нуля) потребляемой из сети реактивной мощности. Но для этого необходимо было стимулировать энергетические службы предприятий и рабочих-станочников к тому, чтобы первые поддерживали баланс электросети за счет установки компенсаторов реактивной мощности, а вторые - обеспечивали полную загрузку электродвигателей рабочих машин и своевременное их отключение.

Соответствующие мероприятия были изложены в «Положении о премировании рабочих и ИТР за повышение коэффициента мощности (косинус «фи»)». В преамбуле Положения - документа, являющегося неотъемлемой частью постановления ГКО № 3945, поясняется, что «премирование имеет своей целью экономию электроэнергии в электросетях, наиболее полное использование электрооборудования промышленных предприятий, повышение пропускной способности электросетей и наиболее полное использование мощностей электростанций» ${ }^{10}$.

В августе-сентябре 1943 г. НКЭС СССР разработал и утвердил шкалу скидок и надбавок к стоимости электроэнергии для промышленных потребителей и правила их применения. В то же время Наркомат электропромышленности приступил к восстановлению производства статических конденсаторов - устройств, предназначенных для компенсации в электросетях предприятий реактивной мощности.

Обкомы ВКП (б) и облисполкомы совместно с энергосистемами организовали социалистическое соревнование промышленных предприятий по экономии электроэнергии. Как сообщается в служебной записке Д.Г. Жимерина в ЦК ВКП (б) на имя Г. М. Маленкова, за период октябрь-декабрь 1943 г. в соцсоревнование было вовлечено 1616 предприятий с электроустановками 100 кВ·А и выше, потребляющих $88 \%$ от всей отпущенной промышленности электроэнергии ${ }^{11}$.

Посредством упорядочения технологии производства, улучшения режима работы электрических печей, увеличения скорости резания металла и т.д. указанные предприятия добились

\footnotetext{
${ }^{9}$ РГАСПИ. Ф.644. ОП.2. Д.205. Л.102.

${ }^{10}$ РГАСПИ. Ф.644. Оп.2. Д.205. Л.109.

${ }^{11}$ РГАЭ. Ф.7964. Оп.2. Д.838. Л.73.
} 
экономии электроэнергии в размере 138 млн кВт.ч, или 3\% от общего полезного отпуска.

По отдельным энергосистемам экономия за IV кв. 1943 г. составила у «Мосэнерго» - 38,4 млн кВт·ч (5,74\%); «Ленэнерго»4,2 (5,2\%); «Азэнерго»-17,1 (5,9\%); «Горэнерго»-13,3 (3,24\%); «Молотовэнерго»-9,8 (3,3\%); «Челябэнерго»-15,6 млн кВт·ч ${ }^{12}$.

Таким образом, не будет преувеличением утверждать, что постановления ГКО от 18 августа 1943 г. № 3944 и № 3945 сыграли исключительно важную роль в обеспечении надежности электроснабжения предприятий оборонно-промышленного комплекса и в повышении экономической эффективности их хозяйственной деятельности в переломный период Великой Отечественной войны.

\section{ГКО распределяет «энергетические» трофеи}

На завершающем этапе Великой Отечественной войны ГКО принимал решения о восстановлении электростанций и линий электропередач в районах, освобожденных от немецко-фашистских оккупантов, и обеспечении их строительными материалами, топливом, оборудованием и запасными частями.

Заслуживает внимания постановление № 4876 «О немедленном начале восстановления плотины и здания Днепрогэса» от 2 января 1944 г. В п. 1 постановления сообщается о передаче строительству Днепровской гидроэлектростанции заготовленных немцами «для восстановления плотины» 10 тыс. т цемента, «хранящегося на территории запорожских заводов» ${ }^{13}$.

Указанный факт подтверждает версию Д. Г. Жимерина о том, что оккупационные власти Германии намеревались использовать ДнепроГЭС, правда, не для электроснабжения населения Украины, а для передачи ее в «фатерланд» посредством сверхдальней воздушной линии электропередачи на высшем в то время напряжении 350-400 кВ, возможно, по системе постоянного тока.

В 1945 г. ГКО принял ряд постановлений о демонтаже и вывозе в СССР с немецких и австрийских электростанций, предприятий и складов энергетического оборудования и электротехнических изделий, в том числе 74 турбин.

${ }^{12}$ РГАЭ. Ф.7964. Оп.2. Д.838. Л.73.

${ }^{13}$ РАГАСПИ. Ф.644. ОП.2. Д.255. Л.122. 
Единственным в стране заводом, где в годы Великой Отечественной войны продолжался выпуск турбоагрегатов, был Уральский турбинный (УТЗ). В 1942 г. на его территории разместились дизельная часть ленинградского Кировского завода и Харьковский турбогенераторный завод. Всего за годы войны УТЗ выпустил 11 турбин суммарной мощностью 176 тыс. кВт. На ряде оборонных предприятий Москвы и Ленинграда с 1943 г. по 1945 г. были восстановлены (отремонтированы) 54 турбины мощностью 932,5 кВт. Это почти равнялось выпуску предвоенного 1940 г. (57 турбин мощностью 971,8 кВт) [Сафронов, 2006].

В ситуации, когда крупнейшие отечественные предприятия энергетического машиностроения по разным причинам прекратили производство профильной продукции, трофейное оборудование способствовало ускорению процесса восстановления электрохозяйства на освобожденной от врага территории.

Например, на Кураховской ГРЭС были установлены турбины мощностью 150 МВт, вывезенные с немецкой электростанции г. Мехталь, а на Каменской ТЭЦ - оборудование электростанции г. Гинденбург мощностью 81 МВт. На Львовскую ГРЭС прибыли турбины, демонтированные с электростанции г. Одерталь (рабочая мощность $30 \mathrm{MBT})^{14}$.

Среди «энергетических» трофеев СССР был совершенно уникальный объект - опытная воздушно-кабельная передача постоянного тока (ППТ) «Эльба - Берлин», запроектированная на мощность 60 МВт и напряжение 40 кВ. Немцы успели смонтировать 1-ю очередь выпрямительной подстанции, с которой в 1945 г. было демонтировано и вывезено в СССР: ртутных выпрямителей АЕГ-120 кВ - 24 шт.; силовых трансформаторов 100 кВ мощностью 12000 кВА - 11 шт.; дросселей на 220 кВ 4 шт.; силового кабеля постоянного тока 220 кВ длиной 191,5 км404 барабана; сигнального кабеля - 222 барабана; изолирующих трансформаторов групповых 220 кВ - 2 шт.; изолирующих трансформаторов индивидуальных 110 кВ - 22 шт. ${ }^{15}$

Вышеуказанное оборудование было использовано при строительстве в 1950 г. первой в СССР опытной линии передачи постоянного тока \pm 100 кВ Кашира-Москва длиной 112 км.

${ }^{14}$ РГАСПИ. Ф.644. Оп.2. Д.454. Л.103.

${ }^{15}$ РГАЭ. Ф.7964. Оп.2. Д.1000. Л.10. 
Изучением немецкого опыта проектирования передач постоянного тока и использования преобразовательного оборудования (ртутные вентили, трансформаторы и т.д.) занимался коллектив созданного в октябре 1945 г. в Ленинграде Института по передаче электроэнергии постоянным током высокого напряжения (НИИПТ).

\section{Краткие выводы}

В годы Великой Отечественной войны советские энергетики, опираясь на утверждаемые ГКО месячные и квартальные лимиты электропотребления, успешно решали задачи гарантированного электроснабжения военной промышленности. Государственная энергетическая политика, проводимая под руководством ГКО CCCP, в целом оказалась достаточно эффективной, как в отношении рационального использования дефицитных энергоресурсов, так и организации лимитированного (по сути - карточного) электроснабжения потребителей.

В 1943 г. благодаря вмешательству ГКО и лично его Председателя И.В. Сталина удалось предотвратить «блэкаут» самой крупной на тот период Уральской энергосистемы и подчинить производственные интересы потребителей - крупнейших предприятий военно-промышленного комплекса - задачам технологически обоснованного оперативно-диспетчерского управления электроэнергетическим режимом.

Приведенные факты, основывающиеся на первоисточниках, свидетельствуют о том, что главным методом воздействия на промышленных потребителей электроэнергии с целью соблюдения дисциплины электроснабжения были денежные взыскания (штрафы) и, как крайняя мера, уголовная ответственность. Для стимулирования экономии электроэнергии промышленными потребителями решениями ГКО также применялись меры поощрения (премирование ИТР и рабочих-станочников за повышение коэффициента мощности электроустановок).

\section{Литература}

Кравченко, Г.С. Экономика СССР в годы Великой Отечественной войны (1941-1945) [Текст]/Г.С. Кравченко. М.: Экономика, 1970. С. 56.

Энергетики в Великой Отечественной войне: Воспоминания старейших энергетиков [Текст]: Сб. статей: Сост. Марина А. М., Котилевский Д. Г., Золотайкина М.А. и др. М.: Энергоатомиздат, 1985. С. 18-19. 
Сафронов, А. А. Становление Уральского турбинного завода им. С. М. Кирова в годы Великой Отечественной войны [Текст]/А.А. Сафронов. Екатеринбург: Изд-во Урал. ун-та, 2006. Вып. 6. С. 248-249.

Статья поступила 03.04.2019.

Для цитирования: Симонов Н.С. Вопросы государственной политики в решениях Госкомитета обороны СССР (1941-1945) //ЭКО. 2019. № 9. С. 104 116. DOI: 10.30680/ECO0131-7652-2019-9-104-116.

\section{Summary}

Simonov, N.S., Doct. Sci. (Histori), PJSC FGC UES, Moscow

Issues of State Energy Policy in Decisions of the USSR State Defense Committee (1941-1945)

Abstract. In the article, for the first time in historiography, a source study analysis of a set of documentary materials relating to the activities of the GKO of the USSR (GKO SSSR) on electric power management in 1941-1945 was carried out. A Schedule of 308 decisions and orders, distributed in nine homogeneous groups of management, was compiled. The historical significance of the GKO solutions dated August 18, 1943 is shown on the issues of alternating current frequency, control in electric power systems and increasing the Power Factor (PF) of electrical installations of industrial enterprises. These decisions taken during the crucial period of the Great Patriotic War prevented the "blackout" of the Ural electric power system and stimulated the producers and consumers of electric power to economical and rational use of energy resources.

Keywords: USSR State Defense Committee; power consumption limits; electric power system; alternating current frequency; power factor $(P F)$ of industrial electrical installations

\section{References}

Kravchenko, G.S. (1970). The economy of the USSR during the Great Patriotic War (1941-1945). Moscow, Ekonomika Publ. P. 56. (In Russ.).

Power Energetics in the Great Patriotic War: Memories of the oldest power engineers (1985). Collection of articles edited by A.M. Marina, D.G. Kotilevskiy, M.A. Zolotaykina and others. Moscow, Energoatomizdat. Pp.18-19. (In Russ.).

Safronov, A.A. (2006). Formation of the Ural turbine plant named after S.M. Kirov during the Great Patriotic War. Yekaterinburg, Publishing house of Ural University, Issue 6. Pp. 248-249. (In Russ.).

For citation: Simonov, N.S. (2019). Issues of state energy policy in decisions of the USSR State Defense Committee (1941-1945). ECO. No. 9. Pp. 104-116. (In Russ.). DOI: 10.30680/ECO0131-7652-2019-9-104-116. 